\title{
A Study of the Va-1 Group of Pseudomonads and its Relationship to Pseudomonas pickettii
}

\author{
By M. J. PICKETT* AND J. R. GREENWOOD \\ Department of Microbiology, University of California, Los Angeles, California 90024, U.S.A.
}

(Received 6 December 1979; revised 23 April 1980)

\begin{abstract}
The Va-1 group of denitrifying pseudomonads was characterized and compared with Pseudomonas pickettii (Va-2). They share many features but differ in their production of acid from cellobiose, lactose and maltose and in their denitrification (gas from nitrate) at $35^{\circ} \mathrm{C}$. DNA-DNA hybridizations between a strain of Va- 1 and the type strain of $P$. pickettii disclosed $84 \%$ homology and hence indicated that Va-1 is a biovar of this species. Since both are potential human pathogens, features are presented that distinguish these and other phenotypically similar species that are recovered from clinical specimens.
\end{abstract}

\section{INTRODUCTION}

Among the groups of non-fermentative Gram-negative rods reported by King (1964), one, group $\mathrm{Va}$, was non-pigmented, oxidase-positive and denitrifying (gas from nitrate). Weaver et al. (1972) reported that strains of the Va group are monotrichous, and that they acidify lactose and maltose but not mannitol, starch and sucrose. Tatum et al. (1974) recognized two biotypes within the Va group, $\mathrm{Va}-1$ and $\mathrm{Va}-2$, only the former acidifying lactose and maltose. Independently, Pickett \& Pedersen $(1970 a)$ examined 22 strains of weakly saccharolytic pseudomonads recovered from clinical specimens and erroneously concluded that they represented a second biotype of Pseudomonas pseudoalcaligenes (Stanier et al., 1966). Several of Pickett \& Pedersen's strains were later examined by Ralston et al. (1973), whose data, covering nutritional properties and DNA base composition and hybridization, indicated that these strains were not closely related to $P$. pseudoalcaligenes but rather represented a distinct species for which they proposed the name Pseudomonas pickettii. Briefly, thereafter, Tatum et al. (1974) and Riley \& Weaver (1975) tentatively equated $P$. pickettii with their Va-2. King et al. (1979), from a cluster analysis of $P$. pickettii, Va-1 and Va-2, concluded that they are closely related. Thus, the similarity of Va-1 and $P$. pickettii is established but the taxonomic position of the former has not been fully clarified. Hence, we report here our observations on this group, compare it with similar non-fermentative bacilli, particularly strains of $P$. pickettii, and record DNA-DNA hybridization of these.

\section{METHODS}

Strains. These were accumulated over a period of 12 years. Most were recovered from clinical specimens in the hospital of the University of California at Los Angeles, U.S.A., although some were received from hospitals throughout the U.S.A. Sources of the Va-1 strains are given in Table 1. Stock cultures were maintained as stabs in a motility-nitrate (MN) medium containing ( ( $\left.^{-1}\right)$ : Heart Infusion Broth (Difco), 5; Tryptose (Difco), 10; agar (Difco), 3; glucose, 0.5; $\mathrm{KNO}_{3}, 1$; sterilization was by autoclaving $\left(121^{\circ} \mathrm{C}\right.$, $10 \mathrm{~min}$ ). Stock cultures were maintained at $4{ }^{\circ} \mathrm{C}$ and transferred fortnightly. Incubation of these and all other cultures was at $35^{\circ} \mathrm{C}$ unless otherwise indicated.

Morphology and growth. Colonial morphology was recorded from cultures grown aerobically for $48 \mathrm{~h}$ on blood agar plates [Difco Blood Agar Base with $5 \%$ (v/v) defibrinated sheep blood]. Microscopic morphology was recorded from Gram-stains (Hucker) prepared from $24 \mathrm{~h}$ cultures on blood agar plates, and from flagellar tains prepared according to Clark (1976). Growth on MacConkey agar (Difco) was determined according 
Table 1. Source of Va-1 strains

Strain Source* (all in U.S.A.)

K-276 UCCL

$\mathrm{K}-300$ UCCL

K-638 UCCL, tracheal aspirate

K-792 Los Angeles, from a cosmetic

K-992 Duarte, California, clinical specimen

K-994 Duarte, California, clinical specimen

K-1303 OVMC

K-1466 Hillcrest Hospital, Petaluma, California

K-1469 Denver, Colorado, hospital environment

K-1502 UCCL, hospital environment (water)

K-1503 UCCL, hospital environment (water)
Strain
Source* (all in U.S.A.)
K-1510 UCCL, hospital environment (water)
K-1515 UCCL, hospital environment (water)
$\mathrm{K}-1532$ OVMC, blood specimen
K-1559 UCCL, hospital environment (water)
K-1560 Denver, Colorado, blood specimen
$\mathrm{K}-1576$ OCHD, aspirate, knee wound
K-1577 OCHD, pericardial fluid
K-1645 OCHD, infected eye
K-1646 OCHD, hospital environment (water)
K-1647 OCHD, hospital environment (water)

* UCCL, UCLA clinical laboratories, Los Angeles; OVMC, Olive View Medical Center, Sylmar, California; OCHD, Orange County (California) Health Department.

to Tatum et al. (1974), and at $42^{\circ} \mathrm{C}$ by lightly inoculating a tube of nitrate broth (Vera \& Dumoff, 1974) and incubating for $48 \mathrm{~h}$. Evidence of motility was observed as spreading growth in both MN and OF (Tatum et al., 1974) media.

Biochemical tests. Acid production from carbohydrates and related compounds was determined in the OF basal medium of Tatum et al. (1974), on the 'oxidative low peptone' (OLP) medium of Greenwood \& Pickett (1978) and by the 'buffered single substrate' (BSS) procedures of Pickett \& Pedersen $(1970 a, b)$. Alkali production from amides and organic salts was determined by OLP and BSS procedures. Commercial BSS tablets (Key Scientific Products, Los Angeles, U.S.A.) were used according to the manufacturer's directions to test for: arginine dihydrolase, $\beta$-galactosidase (the ONPG test), and indole production; hydrolysis of hippurate; oxidation of gluconate to 2-ketogluconate, tryptophan to indolepyruvic acid, and phenylalanine to phenylpyruvic acid; and decarboxylation of lysine and ornithine. Oxidase and catalase were tested according to Greenwood \& Pickett (1979) with cell paste obtained from $24 \mathrm{~h}$ blood agar plates. Formation of fluorescein was detected in King's medium B (Vera \& Dumoff, 1974) supplemented with $0.2 \%$ $(\mathrm{w} / \mathrm{v}) \mathrm{KNO}_{3}$, and in fluorescence-lactose-denitrification (FLN) medium containing $\left(\mathrm{g}^{-1}\right)$ : Proteose Peptone no. 3 (Difco), 10; agar (Difco), 15; lactose, 20; glucose, 0.5; sodium acetate. $3 \mathrm{H}_{2} \mathrm{O}, 0.5$; phenol red, 0.02; $\mathrm{MgSO}_{4} .7 \mathrm{H}_{2} \mathrm{O}, 1.5 ; \mathrm{K}_{2} \mathrm{HPO}_{4}, 1.5 ; \mathrm{KNO}_{3}, 2 ; \mathrm{NaNO}_{2}, 0.5$. This medium was dispensed in $4 \mathrm{ml}$ amounts into $13 \times 100 \mathrm{~mm}$ tubes, sterilized by autoclaving $\left(121^{\circ} \mathrm{C}, 10 \mathrm{~min}\right)$, and solidified to provide slants and butts of approximately equal length. The FLN and MN media used here were modified slightly from those previously reported (Pickett \& Pedersen, 1970a). Hydrolysis of aesculin was detected both with the medium of Vera \& Dumoff (1974) and by disappearance of fluorescence in Kligler iron agar medium supplemented with $0.002 \%$ (w/v) aesculin. Formation of deoxyribonuclease was determined on DNase Test Agar (Difco), of amylase, on the starch agar medium of Vera \& Dumoff (1974) and of gelatinase, on Trypticase Soy Agar (BBL) plates supplemented with $3 \%(\mathrm{w} / \mathrm{v})$ gelatin. Hydrolysis of polysorbate was determined on the following medium (g 1 ${ }^{-1}$ ): Peptone (Difco), 10; agar (Difco), 15; Tween 80 (Sigma), 10; $\mathrm{NaCl}, 5 ; \mathrm{CaCl}_{2} \cdot \mathrm{H}_{2} \mathrm{O}, 0 \cdot 1$. Reduction of nitrate to nitrite was detected in $\mathrm{MN}$ and nitrate broth media, and of nitrate to nitrogen, in FLN, MN, nitrate broth and supplemented King's medium B. Unless otherwise noted, the last two media were incubated at room tenmperature $\left(22 \pm 2{ }^{\circ} \mathrm{C}\right.$ ). Digestion of casein was detected in Skim Milk Broth (Difco), and of serum, on Loeffler's serum slants. Susceptibility to polymyxin B was determined by placing a 300 unit disc (Pfizer) on an inoculated blood agar plate; a zone of complete inhibition of more than $1 \mathrm{~mm}$ (radius) was scored as positive.

Tatum et al. (1974) and Oberhofer et al. (1977) reported that the Va group is urease-positive, whereas others (Pickett \& Pedersen, 1970 $b$; Riley \& Weaver, 1975; King \& Phillips, 1978) reported strain variation within the group. We therefore examined the effect of basal media and size of inocula on the outcome of this test. Stuart et al. (1945), in their studies on Proteus species, used three urea media which differed in respect to concentration of buffer (Table 5), namely their 'usual' (double-strength Sorensen's phosphate, 133.3 mM), ' 0.1 buffered medium' $(13.33 \mathrm{~mm})$ and ' 0.01 buffered medium' $(1.333 \mathrm{~mm})$. They proposed use of the last medium, which is that of Vera \& Dumoff (1974), for rapid urease tests. The urease medium of Key Scientific Products contains $0 \cdot 1 \%(\mathrm{w} / \mathrm{v}) \mathrm{KH}_{2} \mathrm{PO}_{4}(7.4 \mathrm{~mm})$. Christensen and OLP media contain phosphate $(14.7$ and $7.6 \mathrm{~mm}$, respectively) and also $0.1 \%(\mathrm{w} / \mathrm{v})$ each of glucose and organic nitrogen. All of these media contain phenol red as indicator. Each of the buffered substrate media was dispensed in $1 \mathrm{ml}$ amounts in $13 \times 100 \mathrm{~mm}$ tubes and inoculated with $0 \cdot 1 \mathrm{ml}$ of heavy bacterial suspension.

DNA base composition and hybridizations. The methods were those of Greenwood \& Pickett (1980). 


\section{RESULTS}

Colonies of the Va-1 strains were 0.1 to $0.5 \mathrm{~mm}$ in diameter at $24 \mathrm{~h}$ (average for 17 strains, $0.25 \mathrm{~mm}$ ) and enlarged to 0.6 to $1.2 \mathrm{~mm}$ at $48 \mathrm{~h}$ (average, $0.91 \mathrm{~mm}$ ). Colonies of Va-2 strains were slightly larger: 0.3 to $0.8 \mathrm{~mm}$ at $24 \mathrm{~h}$ (average for 13 strains, $0.45 \mathrm{~mm}$ ) and enlarged to 0.8 to $1.4 \mathrm{~mm}$ at $48 \mathrm{~h}$ (average, $1.2 \mathrm{~mm}$ ). The colonies of both biovars at $24 \mathrm{~h}$ were transparent to translucent, non-haemolytic, smooth, convex, entire and butyrous, became translucent to slightly opaque at $48 \mathrm{~h}$ and were not pigmented. Microscopically (see also Tatum et al., 1974), all strains were slender, Gram-negative, monotrichous rods. Also, as noted by Tatum et al. (1974), viability was poor. In our hands, stock cultures of Va-1 maintained at either 4 or $20^{\circ} \mathrm{C}$ frequently died in less than 3 weeks.

Other features of both biovars are presented in Table 2. Only four of the 79 features listed are qualitatively and significantly different for the two biovars, namely, denitrification at $35^{\circ} \mathrm{C}$ and acid production from cellobiose, lactose and maltose. Tables 3 and 4 present additional data concerning the effect of temperature and media on overt production of gas from nitrate.

Table 5 presents results obtained with different media and inocula in tests for hydrolysis of urea. Table 6 presents data obtained from caesium chloride density gradient centrifugation and DNA-DNA hybridization. Table 7 compares $P$. pickettii with those other species which, in our experience, are most likely to be confused with it.

\section{DISCUSSION}

The DNA base composition and hybridization data of Table 6 suggest that both Va-1 and Va-2 are biovars of Pseudomonas pickettii. This suggestion is supported by the cluster analysis of King et al. (1979) and by the hybridization data of Ralston et al. (1973). Ralston et al. (1973) reported that the DNA base composition of strain K-300 of biovar Va-1, like that of type strain K-288 (ATCC 27511) of P. pickettii, was $64 \mathrm{~mol} \% \mathrm{G}+\mathrm{C}$, and that the DNAs of these two strains showed $90 \%$ binding at $71{ }^{\circ} \mathrm{C}$. They also reported that, in assimilation experiments, strain K-300 was similar to the strains of Va-2 but differed in respect of five of the 133 substrates tested (caproate, histamine, L-histidine, L-phenylalanine and valerate).

Tatum et al. (1974) obtained more than two patterns for oxidation of carbohydrates with their strains of group Va but we did not. The discrepancy, we believe, arises from differences in sensitivity between their methods and ours. We, too, found that one out of 17 strains of Va-1 failed to produce acid from lactose in OF medium, a second strain was maltosenegative in this medium, a third was cellobiose-negative in BSS medium, and a fourth was maltose-negative in both BSS and OF media. However, on OLP medium all strains of Va-1 produced acid from all three carbohydrates; no strain of Va-2 produced acid from these carbohydrates with any of the three basal media.

Our results for Va-1 (Table 2) differ from those of Gilardi (1978) in tests for $\beta$-galactosidase (ONPG test) and oxidation of phenylalanine. However, our positive tests were both weak and delayed. We do not, then, judge these to be significant discrepancies.

The data of Table 5 indicate that the concentration of buffer, presence or absence of glucose and size of inoculum may significantly influence the outcome of urease tests on bacteria that are saccharolytic but only weakly urease-positive. All of the strains recorded in this table were urease-positive but none made alkaline the strongly buffered medium of Stuart et al. (1945). With Christensen medium, even when heavily inoculated, only six strains of Va-1 and two strains of Va-2 gave strong (red slant) positive results; the other 12 strains gave only weak (pink slant) positive results during $8 \mathrm{~d}$ incubation.

Since strains of the Va-2 biovar did not denitrify at $35^{\circ} \mathrm{C}$, we determined whether cultures nominally incubated at this temperature would show gas production when they were shifted for different periods to a lower temperature. The data of Table 3 indicate that when relatively 
Table 2. Features of the Va group of pseudomonads

Feature*

Acid from:

Adonitol

Amygdalin

D-Arabinose

L-Arabinose

Arabitol

Arbutin

Cellobiose

Dulcitol

Ethanol

Fructose

Galactose

Glucose

Inositol

Inulin

Lactose

Maltose

Mannitol

Mannose

Melezitose

Melibiose

Raffinose

Rhamnose

Ribose

Salicin

Sorbitol

Starch

Sucrose

Trehalose

Xylose

Alkali from:

Acetamide

Acetate

Allantoin

Asparagine

n-Butyramide

Isobutyrate

n-Butyrate

Citrate, Simmons

Formamide

Formate

Glutamine

Hexanoate

Malonamide

Malonate

Mucate

Nicotinamide

Propionamide

Propionate

Saccharate

Succinamide

Tartrate

Valeramide

Valerate

Arginine dihydrolase

Catalase

DNAase
Va-1

$\overbrace{\begin{array}{c}\text { No. } \\ \text { tested }\end{array}}^{\begin{array}{c}\text { No. } \\ \text { positive }\end{array}} \begin{gathered}\% \\ \text { positive }\end{gathered}$

P. pickettii (Va-2)

$\begin{array}{ccc}\text { No. } & \text { No. } & \% \\ \text { tested } & \text { positive } & \text { positive }\end{array}$

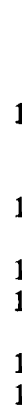

5
5

17

5

5

17

5

15

15

7

17

10

6
19

17

17

7

9

10

8

12

7

8

10

10

17

10

17

13

8

14

10

10

9

9

14

9

10

8

8

17

9

15

11

9

9

10

16

10

9

5

16

$\begin{array}{rrr}0 & 0 & 22 \\ 0 & 0 & 5 \\ 0 & 0 & 5 \\ 17 & 100 & 36 \\ 0 & 0 & 5 \\ 0 & 0 & 7 \\ 17 & 100 & 22 \\ 0 & 0 & 9 \\ 0 & 0 & 16 \\ 15 & 100 & 22 \\ 7 & 100 & 22 \\ 17 & 100 & 22 \\ 0 & 0 & 22 \\ 0 & 0 & 7 \\ 19 & 100 & 36 \\ 17 & 100 & 32 \\ 0 & 0 & 36 \\ 7 & 100 & 22 \\ 0 & 0 & 5 \\ 0 & 0 & 23 \\ 0 & 0 & 8 \\ 0 & 0 & 8 \\ 2 & 29 & 8 \\ 0 & 0 & 8 \\ 0 & 0 & 23 \\ 0 & 0 & 9 \\ 0 & 0 & 8 \\ 0 & 0 & 23 \\ 17 & 100 & 23\end{array}$

$\begin{array}{rr}0 & 0 \\ 0 & 0 \\ 0 & 0 \\ 36 & 100 \\ 0 & 0 \\ 0 & 0 \\ 0 & 0 \\ 0 & 0 \\ 0 & 0 \\ 22 & 100 \\ 22 & 100 \\ 22 & 100 \\ 0 & 0 \\ 0 & 0 \\ 0 & 0 \\ 0 & 0 \\ 0 & 0 \\ 22 & 100 \\ 0 & 0 \\ 0 & 0 \\ 0 & 0 \\ 0 & 0 \\ 0 & 0 \\ 0 & 0 \\ 0 & 0 \\ 0 & 0 \\ 0 & 0 \\ 0 & 0 \\ 23 & 100\end{array}$

$\begin{array}{rr}0 & 35 \\ 100 & 23\end{array}$

100

100

90

100

100

100

0
100

100
100

$0 \quad 23$

100

100

100

0
100

100

100

100

100

94

100

100

0
100

0

0

23
22

22

22


Table 2. (cont)

Feature*

Fluorescence

Gluconate

Growth at $42{ }^{\circ} \mathrm{C}$

Growth on MacConkey agar

Hydrolysis of:

Aesculin

Hippurate

Starch

Tween 80

Urea

Indole

Indolepyruvic acid

Lysine decarboxylase

Motility

Nitrate $\rightarrow$ gas, $35^{\circ} \mathrm{C}$

Nitrate $\rightarrow$ gas, $30^{\circ} \mathrm{C}$

Nitrate $\rightarrow$ nitrite

Ornithine decarboxylase

ONPG

Oxidase

Phenylpyruvic acid

Polymyxin B, susceptible

Proteolysis:

Casein

Gelatin

Serum

\begin{tabular}{|c|c|c|c|c|c|}
\hline \multicolumn{3}{|c|}{ Va-1 } & \multicolumn{3}{|c|}{ P. pickettii (Va-2) } \\
\hline $\begin{array}{l}\text { No. } \\
\text { tested }\end{array}$ & $\begin{array}{c}\text { No. } \\
\text { positive }\end{array}$ & $\begin{array}{c}\% \\
\text { positive }\end{array}$ & $\begin{array}{l}\text { No. } \\
\text { tested }\end{array}$ & $\begin{array}{c}\text { No. } \\
\text { positive }\end{array}$ & $\begin{array}{c}\% \\
\text { positive }\end{array}$ \\
\hline 17 & 0 & 0 & 22 & 0 & 0 \\
\hline 14 & 0 & 0 & 36 & 0 & 0 \\
\hline 15 & 9 & 60 & 22 & 6 & 27 \\
\hline 15 & 15 & 100 & 22 & 22 & 100 \\
\hline 15 & 0 & 0 & 8 & 0 & 0 \\
\hline 15 & 15 & 100 & 10 & 10 & 100 \\
\hline 5 & 0 & 0 & 22 & 0 & 0 \\
\hline 11 & 11 & 100 & 5 & 5 & 100 \\
\hline 16 & 16 & 100 & 14 & 14 & 100 \\
\hline 14 & 0 & 0 & 24 & 0 & 0 \\
\hline 13 & 5 & 38 & 5 & $\mathbf{0}$ & 0 \\
\hline 14 & 0 & 0 & 23 & 0 & 0 \\
\hline 17 & 17 & 100 & 23 & 23 & 100 \\
\hline 15 & 14 & 93 & 13 & 0 & 0 \\
\hline 15 & 14 & 93 & 13 & 13 & 100 \\
\hline 14 & 14 & 100 & 23 & 23 & 100 \\
\hline 9 & 0 & 0 & 12 & 0 & 0 \\
\hline 9 & 9 & 100 & 15 & 0 & 0 \\
\hline 16 & 16 & 100 & 23 & 23 & 100 \\
\hline 8 & 8 & 100 & 5 & 0 & 0 \\
\hline 5 & 0 & 0 & 5 & 0 & 0 \\
\hline 12 & 4 & 33 & 22 & 0 & 0 \\
\hline 9 & 4 & 44 & 22 & 10 & 45 \\
\hline 5 & 0 & 0 & 23 & 0 & 0 \\
\hline
\end{tabular}

* All tests were at $35^{\circ} \mathrm{C}$ unless otherwise indicated.

Table 3. Effect of temperature on production of gas by $P$. pickettii in nitrate broth medium

\begin{tabular}{|c|c|c|c|c|c|c|}
\hline \multirow[b]{2}{*}{ Tube no. } & \multicolumn{3}{|c|}{ Incubation temp./time } & \multicolumn{3}{|c|}{ Gas production* } \\
\hline & $\begin{array}{c}\text { Initial, at } \\
35^{\circ} \mathrm{C} \text { for }(\mathrm{h}):\end{array}$ & $\begin{array}{l}\text { Secondary, at } \\
\text { RT } \dagger \text { for (h): }\end{array}$ & $\begin{array}{l}\text { Final, } \\
\text { at }\left({ }^{\circ} \mathrm{C}\right) \text { : }\end{array}$ & $\begin{array}{l}\text { Va-1 strain } \\
\text { K-638 }\end{array}$ & $\begin{array}{c}\text { Va-2 strain } \\
\text { K-230 }\end{array}$ & $\begin{array}{c}\text { Va-2 strain } \\
\mathrm{K}-288\end{array}$ \\
\hline 1 & 16 & 0 & 35 & + & - & - \\
\hline 2 & 16 & 2 & 35 & + & - & - \\
\hline 3 & 16 & 4 & 35 & + & - & + \\
\hline 4 & 16 & 8 & 35 & + & - & + \\
\hline 5 & 16 & 24 & 35 & + & + & + \\
\hline 6 & 24 & 2 & 35 & + & - & - \\
\hline 7 & 24 & 4 & 35 & + & - & + \\
\hline 8 & 24 & 8 & 35 & + & + & + \\
\hline 9 & 24 & 24 & 35 & + & + & + \\
\hline 10 & 48 & 24 & 35 & + & - & - \\
\hline 11 & 48 & & RT $\dagger$ & + & - & - \\
\hline
\end{tabular}

young ( 16 to $24 \mathrm{~h}$ ) cultures are shifted from $35^{\circ} \mathrm{C}$ to room temperature for as little as $4 \mathrm{~h}$, denitrification may occur. However, older $\left(48 \mathrm{~h}\right.$ or more at $\left.35^{\circ} \mathrm{C}\right)$ cultures did not produce gas in nitrate broth when transferred to the lower temperature. Similar results were obtained with cultures shifted from $35^{\circ} \mathrm{C}$ to $30^{\circ} \mathrm{C}$. We suggest that these data may in part explain the different results reported by different authors in respect of denitrification by strains of $P$. pickettii. 
Table 4. Detection of denitrification* by P. pickettii: effect of medium and temperature

\begin{tabular}{|c|c|c|c|c|c|c|c|c|c|c|c|c|c|}
\hline \multirow{3}{*}{$\begin{array}{l}\text { Incubation } \\
\text { temp. }\left({ }^{\circ} \mathrm{C}\right)\end{array}$} & \multirow{3}{*}{$\underset{\text { medium }}{\text { Basal }}$} & \multicolumn{6}{|c|}{ Va-1 (9 strains) } & \multicolumn{6}{|c|}{ Va-2 (13 strains) } \\
\hline & & \multicolumn{6}{|c|}{ Cumulative $\%$ positive at day: } & \multicolumn{6}{|c|}{ Cumulative $\%$ positive at day: } \\
\hline & & 1 & 2 & 4 & 6 & 8 & 10 & 1 & 2 & 4 & 6 & 8 & 10 \\
\hline 35 & $\mathbf{M N}$ & 0 & 0 & 33 & 33 & 33 & 33 & 0 & 0 & 0 & 0 & 0 & $\mathbf{0}$ \\
\hline 35 & FLN & 11 & 33 & 100 & 100 & 100 & 100 & 0 & 0 & 0 & 0 & 0 & 0 \\
\hline 35 & Peptone & $\mathbf{0}$ & 22 & 78 & 100 & 100 & 100 & $\mathbf{0}$ & $\mathbf{0}$ & 0 & $\mathbf{0}$ & $\mathbf{0}$ & 0 \\
\hline 35 & KBN & 11 & 78 & 100 & 100 & 100 & 100 & 0 & 0 & 0 & 0 & 0 & 0 \\
\hline 30 & MN & 0 & 0 & 44 & 100 & 100 & 100 & 8 & 23 & 62 & 100 & 100 & 100 \\
\hline 30 & FLN & 33 & 100 & 100 & 100 & 100 & 100 & 0 & 54 & 100 & 100 & 100 & 100 \\
\hline 30 & Peptone & 44 & 78 & 89 & 100 & 100 & 100 & 46 & 100 & 100 & 100 & 100 & 100 \\
\hline 30 & KBN & 11 & 33 & 100 & 100 & 100 & 100 & 0 & 23 & 100 & 100 & 100 & 100 \\
\hline $\mathrm{RT} \ddagger$ & $\mathrm{MN}$ & 0 & 0 & 11 & 33 & 78 & 78 & 0 & 0 & 8 & 38 & 77 & 77 \\
\hline RT & FLN & 0 & 0 & 67 & 78 & 78 & 78 & 0 & 0 & 62 & 92 & 100 & 100 \\
\hline RT & Peptone & 0 & 22 & 78 & 100 & 100 & 100 & 0 & 31 & 100 & 100 & 100 & 100 \\
\hline RT & KBN & 11 & 33 & 100 & 100 & 100 & 100 & 0 & 23 & 100 & 100 & 100 & 100 \\
\hline
\end{tabular}

* Overt production of gas from nitrate.

$\dagger$ MN, Motility-nitrate medium; FLN, fluorescence-lactose-denitrification medium; Peptone, $1 \%$ (w/v) peptone with $0.1 \%(\mathrm{w} / \mathrm{v}) \mathrm{KNO}_{3} ; \mathrm{KBN}$, King's medium $\mathrm{B}$ supplemented with $0.2 \%(\mathrm{w} / \mathrm{v}) \mathrm{KNO}_{3}$.

$\ddagger$ RT, Room temperature $\left(22 \pm 2{ }^{\circ} \mathrm{C}\right)$.

Table 5. Comparison of media for urease tests* (at $35^{\circ} \mathrm{C}$ )

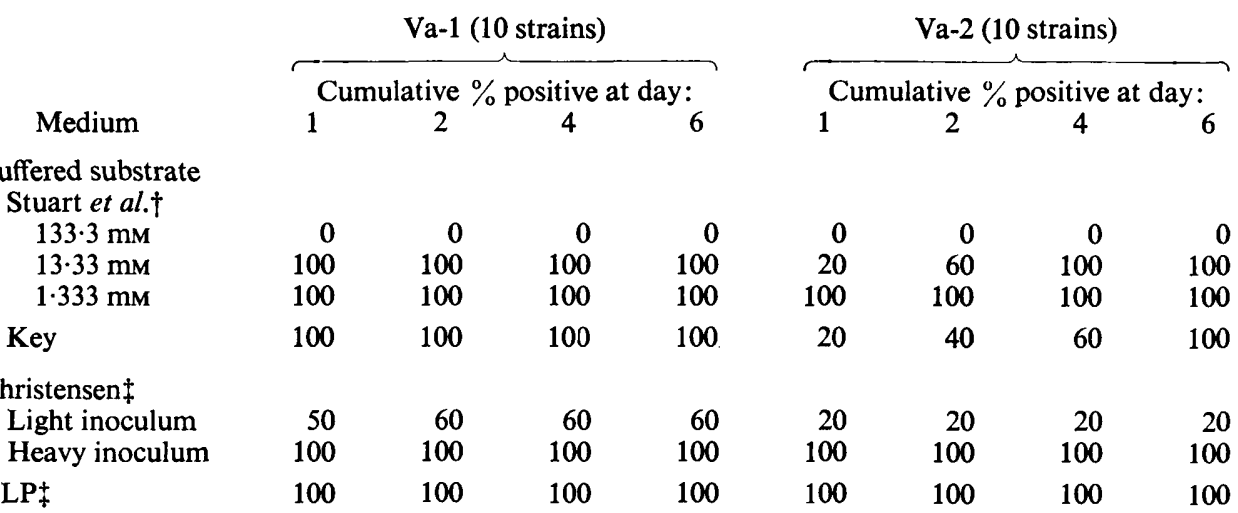

* With Proteus mirabilis, all tests were strongly positive within $24 \mathrm{~h}$.

† See Methods for details of phosphate buffers used by Stuart et al. (1945).

¥ About $2 \mathrm{~mm}^{3}$ of cell paste in a $3 \mathrm{~mm}$ loop was used as 'heavy' inoculum; the same loop, without flaming, provided the 'light' inoculum. A 'light' inoculum was also used for OLP medium.

Table 6. Guanine plus cytosine content and relative binding ratios $(R B R)$ of DNA from strain $\mathrm{K}-638$ of biovar $\mathrm{Va}-1$

\begin{tabular}{lllr}
\multicolumn{1}{c}{ Biovar } & \multicolumn{1}{c}{ Strain } & Mol \% G+C & RBR \\
Va-1 & K-638 & $62 \cdot 9 \pm 0 \cdot 4$ & 100 \\
Va-1 & K-792 & $63 \cdot 3 \pm 0 \cdot 3$ & 74 \\
Va-2 & ATCC 27511/K-288 & $64^{*}$ & 84 \\
CDC M-5 & CDC D1674 & 47 & 0 \\
CDC DF-2 & CDC A3626 & 61 & 0
\end{tabular}

* Datum from Ralston et al. (1973). 
Table 7. Features that distinguish Va from similar non-fermentative bacilli*

\begin{tabular}{|c|c|c|c|c|c|c|c|c|c|c|}
\hline & \multicolumn{3}{|c|}{ 'Achromobacter' $\dagger$} & \multicolumn{6}{|c|}{ Pseudomonas } & \\
\hline & 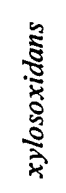 & $\vec{j}$ & $\frac{y}{x}$ & 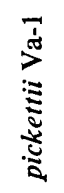 & 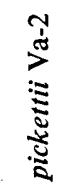 & 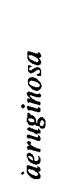 & 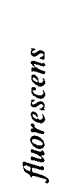 & : & 咅 & 光 \\
\hline Flagella $\ddagger$ & Per & Per & Per & Pol & Pol & Pol & Pol & Pol & Pol & Pol \\
\hline $\begin{array}{l}\text { Polymyxin B, susceptible } \\
\text { Acid from: }\end{array}$ & 100 & 100 & 100 & 0 & 0 & 97 & 96 & 99 & 100 & 0 \\
\hline Ethanol & 100 & ND & 100 & 0 & 0 & 92 & 56 & 86 & 100 & 5 \\
\hline Lactose & 0 & 0 & 0 & 100 & 0 & $\mathbf{0}$ & 47 & 21 & 0 & 100 \\
\hline Maltose & 0 & $\mathbf{0}$ & 100 & 100 & 0 & 4 & 94 & 44 & 100 & 100 \\
\hline Mannitol & 0 & $\mathbf{0}$ & 100 & 0 & 0 & 69 & 94 & 24 & 67 & 0 \\
\hline Sucrose & $\mathbf{0}$ & $\mathbf{0}$ & 100 & 0 & 0 & 0 & 65 & 8 & 0 & 100 \\
\hline Alkali from: & & & & & & & & & & \\
\hline Acetamide & 92 & $\mathbf{0}$ & 0 & 0 & 0 & 100 & $\mathbf{0}$ & 4 & 0 & 0 \\
\hline Malonate & 20 & 0 & 0 & 100 & 100 & 100 & 94 & 56 & 100 & 0 \\
\hline Tartrate & 0 & 20 & 0 & 93 & 100 & 0 & 0 & 43 & 0 & 16 \\
\hline Arginine dihydrolase & 0 & 25 & 0 & 0 & 0 & 99 & 99 & 98 & 2 & 0 \\
\hline Fluorescence: & & & & & & & & & & \\
\hline $20-30{ }^{\circ} \mathrm{C}$ & 0 & 0 & 0 & 0 & 0 & 91 & 100 & 100 & 0 & 0 \\
\hline $35-37^{\circ} \mathrm{C}$ & 0 & 0 & 0 & 0 & 0 & 94 & 47 & 60 & 0 & 0 \\
\hline Gluconate & 96 & 0 & 0 & $\mathbf{0}$ & 0 & 92 & 96 & 87 & 0 & 0 \\
\hline Hydrolysis of: & & & & & & & & & & \\
\hline Aesculin & 0 & $\mathbf{0}$ & 100 & 0 & $\mathbf{0}$ & 0 & 0 & 0 & 0 & 95 \\
\hline Starch & 0 & 0 & 0 & 0 & 0 & 1 & 5 & 7 & 93 & 95 \\
\hline Tween 80 & 0 & 0 & 0 & 100 & 100 & 69 & 54 & 1 & 100 & 48 \\
\hline Nitrate $\rightarrow$ gas, $20-30^{\circ} \mathrm{C}$ & 77 & 100 & 100 & 93 & 100 & 58 & 6 & 0 & 100 & 0 \\
\hline Nitrate $\rightarrow$ nitrite & 98 & 100 & 100 & 100 & 100 & 40 & 14 & 0 & 100 & $\mathbf{0}$ \\
\hline Urea, Christensen & 0 & 100 & 100 & 100 & 100 & 72 & 42 & 51 & 16 & 100 \\
\hline
\end{tabular}

Numbers indicate the percentage of strains positive; ND, no data.

* Data from Table 2, Oberhofer et al. (1977), G. L. Gilardi (personal communication, 1979), and our unpublished studies.

$\dagger$ The genus Achromobacter, though not recognized in the 8th edition of Bergey's Manual of Determinative Bacteriology, is used here in the sense of Tatum et al. (1974).

$\ddagger$ Per, Peritrichous; Pol, polarly flagellated.

In the identification of non-fermentative Gram-negative rods, differentiation among 'Achromobacter' species, $P$. pickettii and the Pseudomonas fluorescens- $P$. putida complex can present a problem, particularly if incubation is at 35 to $37^{\circ} \mathrm{C}$ since the last group frequently fails to show fluorescence at this temperature. For this last group, sensitivity to polymyxin $\mathrm{B}$, production of alkali from arginine and formation of fluorescein at room temperature are a critical constellation of features. Although we are aware of the uncertain future of the genus Achromobacter (see Hendrie et al., 1974), we use the name here since many clinical microbiologists feel that this would be a useful genus in which to include peritrichously flagellated oxidative organisms. For Achromobacter species, possession of peritrichous flagella is the one most useful feature. When this information is not available, failure to hydrolyse Tween 80 is particularly useful. Other useful features are reduction of nitrate to nitrite or gas, a negative arginine test and susceptibility to polymyxin B. Among all non-fermentative bacilli, $P$. pickettii is uniquely characterized by the following features: resistance to polymyxin $\mathrm{B}$; acid from glucose but never from ethanol, mannitol and sucrose; alkali from malonate and urea; and gas from nitrate $\left(20\right.$ to $\left.30^{\circ} \mathrm{C}\right)$.

As with many non-fermentative bacilli, there are few firm data concerning the aetiologic significance of Va-1 in human disease. Most of our strains appeared to represent normal flora of the hospital environment. However, both K-1576 and K-1577 (Table 1) were 
recovered from active disease processes and the latter strain was recovered in pure culture. Tentatively, then, we conclude that Va-1, like several other non-fermentative species (Pedersen et al., 1970), is occasionally aetiologically significant in human disease.

Since completion of this paper a further five strains of $\mathrm{Va}-1$ have been isolated from clinical specimens.

\section{REFERENCES}

Clark, W. A. (1976). A simplified Leifson flagella stain. Journal of Clinical Microbiology 3, 632-634.

Gilardi, G. L. (1978). Identification of Pseudomonas and related bacteria. In Glucose Nonfermenting Gram-Negative Bacteria in Clinical Microbiology, pp. 15-44. Edited by G. L. Gilardi. West Palm Beach, Fla: CRC Press.

Greenwood, J. R. \& Pickett, M. J. (1978). Gramnegative nonfermentative bacilli: rapid identification of commonly encountered species. Abstracts of the Annual Meeting, American Society for Microbiology, p. 290.

Greenwood, J. R. \& Pickett, M. J. (1979). Salient features of Haemophilus vaginalis. Journal of Clinical Microbiology 9, 200-204.

Greenwood, J. R. \& PicketT, M. J. (1980). Transfer of Haemophilus vaginalis Gardner and Dukes to a new genus, Gardnerella: G. vaginalis (Gardner and Dukes) comb. nov. International Journal of Systematic Bacteriology 30, 170-178.

Hendrie, M. S., Holding, A. J. \& Shewan, J. M. (1974). Emended descriptions of the genus Alcaligenes and of Alcaligenes faecalis and proposal that the generic name Achromobacter be rejected: status of the named species of Alcaligenes and Achromobacter. International Journal of Systematic Bacteriology 24, 534-550.

KING, A. \& PhILlips, I. (1978). The identification of pseudomonads and related bacteria in a clinical laboratory. Journal of Medical Microbiology 11, 165-176.

King, A., Holmes, B., Phillips, I. \& Lapage, S. P. (1979). A taxonomic study of clinical isolates of Pseudomonas pickettii, 'P. thomasii' and 'Group IVd' bacteria. Journal of General Microbiology 114, 137-147.

KING, E. O. (1964). The Identification of Unusual Pathogenic Gram Negative Bacteria. Atlanta, Ga, U.S.A.: Communicable Disease Center.

Oberhofer, T. R., Rowen, J. W. \& CunNingham, G. F. (1977). Characterization and identification of gram-negative, nonfermentative bacteria. Journal of Clinical Microbiology 5, 208-220.

Pedersen, M. M., Marso, E. \& Pickett, M. J.
(1970). Nonfermentative bacilli associated with man: III. Pathogenicity and antibiotic susceptibility. American Journal of Clinical Pathology 54, 178-192.

Pickett, M. J. \& Pedersen, M. M. (1970a). Characterization of saccharolytic nonfermentative bacteria associated with man. Canadian Journal of Microbiology 16, 351-362.

Pickett, M. J. \& Pedersen, M. M. (1970 b). Salient features of nonsaccharolytic and weakly saccharolytic nonfermentative rods. Canadian Journal of Microbiology 16, 401-409.

Ralston, E., Palleroni, N. J. \& Doudoroff, M. (1973). Pseudomonas pickettii, a new species of clinical origin related to Pseudomonas solanacearum. International Journal of Systematic Bacteriology 23, 15-19.

Riley, P. S. \& WeAver, R. E. (1975). Recognition of Pseudomonas pickettii in the clinical laboratory: biochemical characterization of 62 strains. Journal of Clinical Microbiology 1, 61-64.

Stanier, R. Y., Palleroni, N. J. \& Doudoroff, M. (1966). The aerobic pseudomonads: a taxonomic study. Journal of General Microbiology 43, 159271.

Stuart, C. A., van Stratum, E. \& Rustigian, R. (1945). Further studies on urease production by Proteus and related organisms. Journal of Bacteriology 49, 437-444.

Tatum, H. W., Ewing, W. H. \& Weaver, R. E. (1974). Miscellaneous gram-negative bacteria. In Manual of Clinical Microbiology, 2nd edn, pp. 270-294. Edited by E. H. Lennette, E. H. Spaulding \& J. P. Truant. Washington, D.C.: American Society for Microbiology.

VERA, H. D. \& DumofF, M. (1974). Culture media. In Manual of Clinical Microbiology, 2nd edn, pp. 881-929. Edited by E. H. Lennette, E. H. Spaulding \& J. P. Truant. Washington, D.C.: American Society for Microbiology.

Weaver, R. E., Tatum, H. W. \& Hollis, D. G. (1972). The Identification of Unusual Pathogenic Gram Negative Bacteria. Atlanta, Ga, U.S.A.: Center for Disease Control. 